\title{
Von Willebrand Disease, Type 2B
}

National Cancer Institute

\section{Source}

National Cancer Institute. von Willebrand Disease, Type 2B. NCI Thesaurus. Code C131687.

An autosomally inherited (generally dominant) coagulation disorder characterized by qualitative abnormalities of the von Willebrand factor (VWF). The mutant VWF shows increased affinity to platelet glycoprotein Ib alpha, resulting in increased platelet aggregation, and increased proteolysis of VWF subunits causing a decrease of large VWF multimers; patients often have secondary thrombocytopenia due to platelet consumption. 